\title{
Effect of Task-oriented Training and Neurodevelopmental Treatment on the Sitting Posture in Children with Cerebral Palsy
}

\author{
Munhee Choi, PhD, PT ${ }^{1)}$, DAehee Lee, PhD, PT ${ }^{2)}$, Hyolyun Ro, PhD, $\mathrm{PT}^{3)}$ \\ 1) Department of Physical Therapy, Daedong hospital \\ 2) Department of Physical Therapy, Youngdong University \\ 3) Department of Occupational Therapy, Kangwon National University: Hwangio-ri, Samcheok-si, \\ Gangwondo, 240-907 Republic of Korea. \\ TEL: +82 33-540-3481, FAX: +82 33-572-8620,E-mail: withtry@kangwon.ac.kr
}

\begin{abstract}
Purpose] The purpose of this study was to investigate the effect of task-oriented training and neurodevelopmental treatment (NDT) on the sitting posture of children with cerebral palsy. [Subjects] The subjects were 10 children with spastic diplegia and cerebral palsy due to premature birth. [Methods] The control group $(n=5)$ received NDT and the experimental group $(\mathrm{n}=5)$ received the task oriented approach to improve sitting balance control, 5 times per week for 6 weeks. Sitting posture was assessed the gross motor functional measure (GMFM), and electromyography (EMG) pre and post intervention. [Results] GMFM and right rectus abdominis activities showed no significant differences in either treatment. The activity strength of the left rectus abdominis, right and left erector muscles significantly increased in both groups. With regard to the difference in the GMFM and EMG between the experiment and control groups, there was no difference. [Conclusion] The results of this study suggest that the method of task-oriented training and neurodevelopmental treatment for muscle vitalization both improved the sitting posture of children with cerebral palsy.
\end{abstract}

Key words: Sitting posture, Spastic diplegia, Task-oriented training

(This article was submitted Sep. 22, 2010, and was accepted Oct. 26, 2010)

\section{INTRODUCTION}

To maintain a sitting posture, control by the trunk is essential. When the upper limbs move around the center line, the trunk plays the role of a base and "postureregulator," thereby balancing the body ${ }^{1}$. Among the trunk muscles, the rectus abdominis and erector spinae play major roles in controlling the sitting posture ${ }^{2)}$. Children with cerebral palsy (CP) have difficulty in posture control because of primary damage to the nervous system and secondary effects on the musculoskeletal system. In particular, children with spastic diplegic CP have excess muscle tonus around the lower limbs and pelvis. They also have difficulty in posture control, muscle coordination disorder, muscle weakness, motor control disorder, sensory disturbance, and muscle contracture. The difficulty with posture control owing to these abnormalities is obvious and consequently, functional movement while sitting is limited ${ }^{3}$. Recent movement control theories suggest that treatment with functional tasks that involve identification of movements is more effective than the simple practice of movements. The movement is learnt efficiently when the patient actively tries to resolve the problems posed by the functional tasks ${ }^{4}$. Neurodevelopmental treatment (NDT) is the most commonly used treatment for children with $\mathrm{CP}$, and many studies have reported its effects. Against this background, in this study, we evaluated changes in after the gross motor function measure (GMFM) scores and the extent of muscle vitalization in the sitting posture conducting task-oriented training for children with spastic diplegic CP, in order to reveal the efficiency of the functional task-oriented treatment approach.

\section{SUBJECTS AND METHODS}

Ten children with spastic diplegic $\mathrm{CP}$ aged between 2 and 9 years were randomly assigned to either an experiment group ( 2 boys and 3 girls, mean gestational period $=31.60$ weeks, average age $=41.20$ months $)$ or a control group ( 3 boys and 2 girls, mean gestational period $=30.20$ weeks, average age $=48.11$ months). They attended ' $D$ Clinic' and 'B Disabled Welfare Center' in ' $B$ ' City in Korea. The selection criteria for the inclusion of these children in the study were as follows: Confirmed diagnosis of spastic diplegic CP due to premature birth and a diagnosis of periventricular leukomalacia confirmed by magnetic 
Table 1. Comparison of the GMFM value

\begin{tabular}{lcccc}
\hline \multirow{2}{*}{ Group } & Pre-intervention & Post-intervention & & U \\
\cline { 2 - 3 } & Subject Score & Subject Score & & \\
\cline { 2 - 3 } Experimental group & 30 & 47 & & \\
& 61 & 50 & & \\
Total & 27 & 60 & & \\
& 15 & 35 & & \multirow{2}{*}{1.83} \\
Control & $34.60 \pm 16.94$ & $44.00 \pm 12.62$ & & \\
group & 60 & 60 & & \\
& 50 & 55 & & \\
& 60 & 60 & & \\
Total & 52 & 55 & & \\
\hline
\end{tabular}

resonance imaging; Ability to perform other movements in addition to sitting, i.e., the B items listed among the GMFM items; Ability to comprehend instructions given by the trainers; Parent's consent to participation of their wards in the study after having read the "experiment participation agreement" and "guide to the experiment". The control group received NDT, and the experimental group received the task oriented approach for improving sitting posture control 30 min per session, 5 times per week for 6 weeks. Three pediatric physical therapists (one tester and two therapists) also participated in this study. Assessments were conducted by a physical therapist. The therapists who conducted the examinations were trained in the test procedure, and were blind to the group assignment of the children. The pace of the task-oriented training program was such that it allowed the subjects to perform the tasks comfortably ${ }^{2)}$. For tasks involving stretching of the pelvis/ lower limbs and those for improving the control of muscle tonus through a separation movement, the methods of Day et al. $(2004)^{5)}$ and Carr \& Shepherd $(1998)^{6)}$ were adopted. Muscle power training with a ring was employed to strengthen the lower trunk muscles and lower limb muscles. For this purpose, the methods of Langhammer $(2003)^{4)}$ and Carr \& Shepherd (1998) $\left.{ }^{6}\right)$ were adopted. The ring-holding task was undertaken to enable the movement of the lower limbs, while inhibiting an increase in the muscle tonus of the upper limbs, as the children maintained the trunk balance between front/rear and left/right. The methods of Tecklin $(1999)^{7)}$ and $\mathrm{Wu}$ et al. ${ }^{8}$ were adopted for this program ${ }^{4}$. For the task that involved standing up from a sitting position, the methods of Day et al. $(2004)^{5)}$ and Dean $(2000)^{9)}$ were adopted. A task performed using balls was adopted from the work of Dean $(2000)^{9)}$ and Michaelsen $(2006)^{10)}$. While sitting, the children spontaneously control the extent of the body movement by using a treatment ball. This task increases the children's concentration ${ }^{11)}$. Individuals were assessed before and after treatment, using the GMFM and electromyography (EMG). EMG measures the degree of activity of the tested muscles. In this experiment, we conducted GMFM tests in the B category (sitting) to evaluate the improvement in movement ability. The GMFM took 5 minutes in this study. The reliability among users of the Korean version of the GMFM is 0.76 to $0.98^{11)}$.

Electromyograms of the rectus abdominus and erector spinae muscles were obtained using Surface EMG Signal MP150 WSW (BIOPAC System Inc. CA, USA). MediTrace Mini Electrodes (Ludlow Technical Products Canada, Ltd.) were used. The quantification of the collected signals during the contraction of each muscle was achieved by the root mean square method. The degree of muscle vitalization was analyzed by measuring the muscle activity for 1 second ${ }^{12)}$. The methods used for the measurement of posture and movement were those reported by $\mathrm{Cram}^{13)}$. Nonparametric statistics were used; the Wilcoxon signed rank test was used to identify differences between before and after the treatment and the Mann Whitney U-test was employed to identify differences between the 2 groups. SPSS for Win 12.0 was used for the analyses, and differences were considered significant at values of $\alpha<0.05$.

\section{RESULTS}

The B category score in the GMFM and right rectus abdominis muscles activity did not improve in either group with treatment. However, the activity strength of the left rectus abdominis muscles, right and left erector muscles had significantly increased in both groups after treatment $(p<0.05)$. They were no differences in the GMFM and EMG between the experiment and control groups. (Table 1,2).

\section{DISCUSSION}

In this study, task-oriented training and NDT were conducted with children with $\mathrm{CP}$, and the degree of muscle vitalization in the sitting posture and GMFM were evaluated. The children performed intensive tasks which are effective for improving the muscular strength and increases functional activity in children with $\mathrm{CP}^{14)}$. Dean et al. (1997) ${ }^{15)}$ reported increased reaching arm and muscular activation on the lower extremity after task-oriented training. In this 
Table 2. Comparison of the RMS value

\begin{tabular}{lccccc}
\hline & & \multicolumn{4}{c}{$\mathrm{M} \pm \mathrm{SD}$} \\
& Group & Pre- intervention & Post- intervention & $\mathrm{Z}$ & $\mathrm{U}$ \\
\hline Rt Rectus & Experimental group & $6.37 \pm 0.64$ & $18.20 \pm 10.21$ & 1.75 & \multirow{2}{*}{1.149} \\
Abdominis $(\mu \mathrm{V})$ & Control group & $7.61 \pm 3.28$ & $10.64 \pm 6.01$ & -0.94 & \\
\hline Lt Rectus & Experimental group & $8.47 \pm 5.17$ & $18.23 \pm 13.70$ & $2.02^{*}$ & \multirow{2}{*}{1.567} \\
Abdominis $(\mu \mathrm{V})$ & Control group & $4.41 \pm 2.08$ & $7.10 \pm 4.54$ & $2.02^{*}$ & \\
\hline Rt Erector & Experimental group & $7.00 \pm 2.77$ & $8.22 \pm 2.88$ & $2.02^{*}$ & \multirow{2}{*}{1.567} \\
Spinae $(\mu \mathrm{V})$ & Control group & $6.69 \pm 2.03$ & $10.58 \pm 1.31$ & $2.02^{*}$ & \\
\hline Lt Erector & Experimental group & $4.66 \pm 0.67$ & $6.35 \pm 0.87$ & $2.02^{*}$ & \multirow{2}{*}{1.567} \\
Spinae $(\mu \mathrm{V})$ & Control group & $6.66 \pm 2.58$ & $9.45 \pm 2.70$ & $-2.02^{*}$ & \\
\hline
\end{tabular}

$* \mathrm{p}<0.05$.

study, both groups showed a significant increase in muscle vitalization, especially that of the erector spinae muscles after treatment, but there were no difference with regard to the difference in the GMFM and EMG between the experiment and control groups. Analysis of the electromyographic findings revealed no significant difference in the rectus abdominis muscles; however, the erector spinae muscles showed a significant increase in the amplitude after treatment. Several studies have been conducted on muscle vitalization, especially that of the erector spinae muscles because of the importance of body dynamics and the muscles that are involved in the sitting posture ${ }^{16)}$. Van der Heide et al. ${ }^{2)}$ measured the trunk muscle activity of children with $\mathrm{CP}$ of school age. They found that although the rectus abdominis muscles were inactive in most cases, the erector spinae muscles and some inner abdominal oblique muscles were vitalized. This may be related to the fact that school-age children have to spend long hours sitting and they overuse their erector spinae muscles to maintain the sitting posture. The task-oriented training, which incorporates several daily movements, can be used as a treatment strategy to improve posture control. Through such a training, patients can learn various ways to resolve the tasks, and these tasks are more effective than simple muscle patterns. Our results suggest that the taskoriented treatment and NDT for children with CP yield improvements in their muscle vitalization during sitting. However, this result cannot be generalized from this research because the study population was too small.

\section{REFERENCES}

1) Coluccini M, Maini ES, Martelloni C, et al.: Kinematic characterization of functional reach to grasp in normal and in motor disabled children. Gait Posture. 2007, 25: 493-501.

2) Van der Heide JC, Otten B, van Eykern LA, et al.: Development of postural adjustments during reaching in sitting children. Exp Brain Res. 2003, 151:3245.

3) Van der Weel FRR, Van der Meer ALH, Lee DN: Measuring dysfunction of basic movement control in cerebral palsy. Hum Mov Sci. 1996, 15: 253-283.

4) Langhammer B, Stanghelle JK: Bobath or motor relearning programme?: a follow-up one and four year post stroke. Clin Rehabil. 2003, 17: 731-734.

5) Day JA, Fox EJ, Lowe J, et al.: Locomotor training with partial body weight support on a treadmill in a nonambulatory child with spastic tetraplegic cerebral palsy: a case report. Pediatr Phys Ther. 2004, 16: 106-113.

6) Carr JH, Shepherd RB: Neurological Rehabilitation: Optimizing Motor Performance (1st ed). Oxford: Butterworth-Heinemann, 1998, p159.

7) Tecklin JS: Pediatric Physical Therapy. (3rd ed). Philadelphia, Lippincott Williams \& Wilkins, 1999, pp 11-20.

8) Wu CY, Wong MK, Lin KC, et al.: Effects of task goal and personal preference on seated reaching kinematics after stroke. Stroke. 2001, 32: 7076.

9) Dean CM, Richards CL, Malouin F: Task-related circuit training improves performance of locomotor tasks in chronic stroke: a randomized, controlled pilot trial. Arch Phys Med Rehabil. 2000, 81: 409-417.

10) Michaelsen SM, Dannenbaum R, Levin MF: Task-specific training with trunk restraint on arm recovery in sroke: randomized control trial. Stroke. 2006, 37: 186-192.

11) Park SY, Ko MS, Yi CH: Correlations Among GMFM, GMPM, and the Spatiotemporal Gait Parameters. Journal of the Korean Academy of University Trained Physical Therapists, 2004, 11: 63-70.

12) Chung YJ, Cho SH, Lee JH et al.: Reliability of the onset time determinations during maximal isometric contraction in surface EMG . Journal of Korea Academy of University Trained Physical Therapists, 2003, 10: 51-62.

13) Cram JR, Kasman JS, Holtz J: Introduction to Surface Electromyography (2nd ed). Maryalnd, Aspen Publishers, 1998, pp 336-345.

14) Blundell SW, Shepherd RB, Dean CM, et al.: Functional strength training in cerebral palsy: a pilot study of a group circuit training class for children aged 4-8year. Clin Rehabil, 2003. 17: 48-57.

15) Dean CM, Shephered RB: Task-related training improves performance of seating reaching tasks after stroke: a randomised controlled trial. Stroke, 1997, 28: 722-728.

16) Kim SS, Song JC: Trunk muscle activites of standing and sitting posture in children with cerebral palsy. The Journal of Korean Society of Physlicl Therapy, 2004, 16: 367-372. 